\title{
Nod Factors Alter the Microtubule Cytoskeleton in Medicago truncatula Root Hairs to Allow Root Hair Reorientation
}

\author{
Björn J. Sieberer, ${ }^{1}$ Antonius C. J. Timmers, ${ }^{2}$ and Anne Mie C. Emons ${ }^{1}$ \\ ${ }^{1}$ Laboratory of Plant Cell Biology, Wageningen University, Arborteumlaan 4, 6703 BD Wageningen, The Netherlands; \\ 2Laboratoire des Interactions Plantes Microorganismes, CNRS/INRA, BP 27, 31326 Castanet-Tolosan Cedex, France
}

Submitted 20 December 2004. Accepted 11 July 2005.

\begin{abstract}
The microtubule (MT) cytoskeleton is an important part of the tip-growth machinery in legume root hairs. Here we report the effect of Nod factor (NF) on MTs in root hairs of Medicago truncatula. In tip-growing hairs, the ones that typically curl around rhizobia, NF caused a subtle shortening of the endoplasmic MT array, which recovered within $10 \mathrm{~min}$, whereas cortical MTs were not visibly affected. In growth-arresting root hairs, endoplasmic MTs disappeared shortly after NF application, but reformed within 20 min, whereas cortical MTs remained present in a high density. After NF treatment, growtharresting hairs were swelling at their tips, after which a new outgrowth formed that deviated with a certain angle from the former growth axis. MT depolymerization with oryzalin caused a growth deviation similar to the NF; whereas, combined with NF, oryzalin increased and the MT-stabilizing drug taxol suppressed NF-induced growth deviation. The NF-induced disappearance of the endoplasmic MTs correlated with a loss of polar cytoarchitecture and straight growth directionality, whereas the reappearance of endoplasmic MTs correlated with the new set up of polar cytoarchitecture. Drug studies showed that MTs are involved in determining root hair elongation in a new direction after NF treatment.
\end{abstract}

The symbiosis between leguminous plants and rhizobia leads to the formation of a new organ, the $\mathrm{N}_{2}$-fixing root nodule. The different steps involved in the establishment of the symbiosis between these two organisms are tightly controlled through a complex network of signaling cascades (Cullimore and Dénarié 2003; Endre et al. 2002; Geurts 2003; Limpens et al. 2003; Madsen et al. 2003; Parniske and Downie 2003; Radutoiu et al. 2003; Stracke et al. 2002). Nod factors (NFs) are signal molecules secreted by rhizobia which have been shown to be essential for successful symbiosis (Fisher and Long 1992; Lerouge et al. 1990; Roche et al. 1991; Spaink et al. 1991; Truchet et al. 1991). One of the first essential steps in the infection process is the curling of root hairs around the bacteria (Esseling et al. 2004; Hadri and Bisseling 1998; Kijne 1992). Van Batenburg and associates (1986) proposed that root hair tip growth is essential for root hair curling. Recently, hair curling has been described as iterative tip growth reorientation (Esseling et al. 2003).

Corresponding author: A. M. C. Emons; E-mail: annemie.emons@wur.nl B. J. Sieberer and A. C. J. Timmers contributed equally to this work.
It has been shown that the actin cytoskeleton is a target of NFs (Medicago sativa [Allen et al. 1994], Phaseolus vulgaris [Cárdenas et al. 1998, 2003], and Vicia sativa [De Ruijter et al. 1998; Miller et al. 1999; Ridge 1992]). During root hair curling of Medicago spp. root hairs inoculated with Sinorhizobium meliloti, endoplasmic microtubules (EMTs) are present between the nucleus and the root hair tip of the curl, concentrate at the infection site where bacteria enter the root hair, and are present between the nucleus and the tip of the infection thread during infection thread growth in the root hair shank (Timmers 2000). Despite these findings, the responses of the microtubule (MT) cytoskeleton shortly after application of NF and their function in the early infection process remained elusive.

Elongating legume root hairs have EMTs in their subapex (V. hirsuta [Lloyd et al. 1987]) that are organized in an extensive array (M. truncatula [Sieberer et al. 2002] and $M$. sativa [Weerasinghe et al. 2003]), which they acquire when tip growth begins and retain until growth stops (Sieberer et al. 2002). In contrast to legume root hairs, in growing Arabidopsis spp. hairs, the subapical array of EMTs consists of a few bundles of MTs (Van Bruaene et al. 2004).

In the root hair deformation assay, in which NFs are applied globally to roots in a glass microchamber, the so-called Fåhraeus slides (Fåhraeus 1957), only growth-arresting root hairs respond with root hair deformation ( $V$. sativa [De Ruijter et al. 1998; Heidstra et al. 1994] and M. truncatula [Sieberer and Emons 2000]), which consists of swelling of the root hair tip (i.e., temporary switch to isodiametric growth) and formation of a new outgrowth from the swelling (i.e., reinitiation of tip-growth) (V. sativa [De Ruijter et al. 1998] and M. truncatula [Sieberer and Emons 2000]). In Arabidopsis spp. root hairs, a pulse application of actin depolymerizing drugs causes swelling, from which tip growth resumes in the original growth orientation (Ketelaar et al. 2003). When the same treatment with actin depolymerizing drugs is performed in Arabidopsis hairs where MTs were experimentally ablated, the new axis of cell elongation deviates from the original growth axis by a certain angle (Ketelaar et al. 2003). The newly formed outgrowth after NF-induced root hair swelling also deviates at a certain angle from the original growth axis. This is an indication that MTs are NF effectors. Here, we report the effect of NFs, the MT depolymerizing drug oryzalin, the MT stabilizing drug taxol, and combinations of these agents on MT arrays and cell growth of M. truncatula root hairs. MTs were visualized by immunocytochemistry after rapid freeze fixation as well as with a green-fluorescent protein MT binding domain (GFP-MBD) fusion protein decoration in living root hairs. 
Our findings show that the MT cytoskeleton contributes to root hair morphology, determines cytoplasmic polarity in elongating hairs, and, therefore, is an essential part of the tipgrowth machinery. It appears to be a direct or indirect target of early NF signaling, and its dynamics a prerequisite for root hair reorientation upon NF perception.

\section{RESULTS}

Effects of Nod factor on the MT cytoskeleton and the cytoarchitecture of elongating root hairs.

Within 3 to 5 min after NF application, we observed a subtle and transient shortening of the three-dimensional and dense EMT array in the subapex of tip-growing hairs (Fig. 1B compared with $\mathrm{C}, \mathrm{F}$, and $\mathrm{H}$ ) that was completely restored within 10 to $15 \mathrm{~min}$. The restored EMT array remained present until regular growth termination (data not shown), which was the same as in control root hairs. At 5 min after NF treatment, the EMT array at the basal part of the subapical region had almost completely disappeared (Fig. 1C) or become less dense (Fig. $1 \mathrm{~F}$ and $\mathrm{H}$ ) in approximately $76 \%$ of the observed hairs (Table
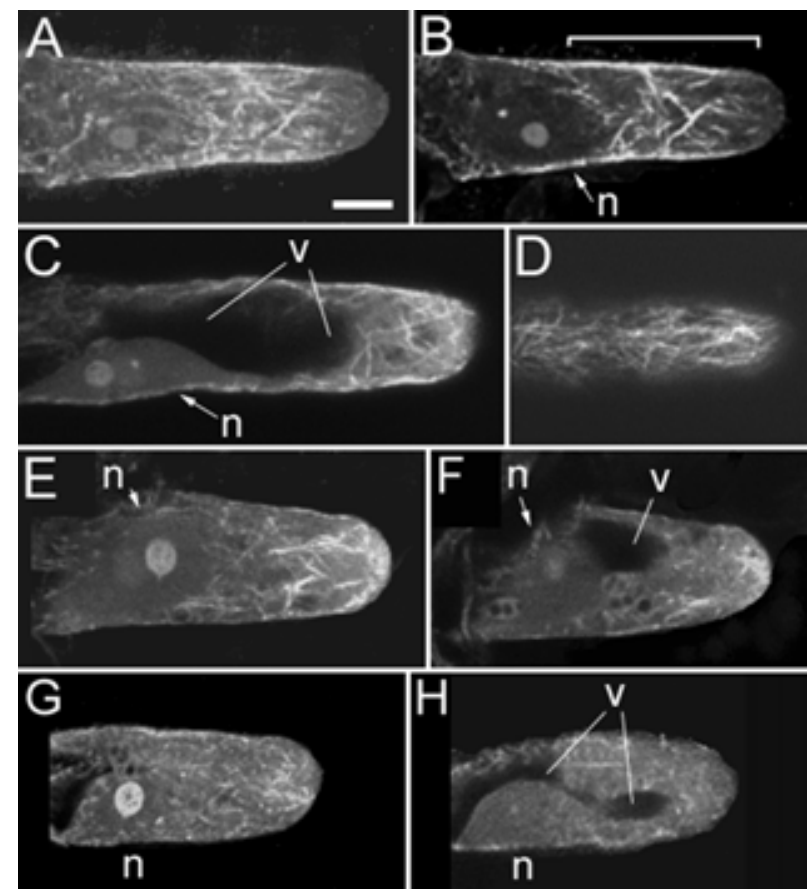

Fig. 1. Microtubules (MTs) in untreated and Nod factor (NF)-treated tipgrowing Medicago truncatula root hairs. A, Full-stack projection; cortical MTs (CMTs) are net-axially oriented and do not reach the very tip of the hair. B, Median section of the same hair shows endoplasmic MTs (EMTs) in the subapex of the hair (bracket). C, Projection of two median scans shows a short EMT array in the subapex (compare with B). The vacuole has overtaken the nucleus and occupies a large part of the space between nucleus and tip, where the EMT array normally spreads. D, Projection of two cortical scans of the hair in C shows that CMTs are not obviously affected shortly after NF treatment. E, In a single optical section, the EMT array and the cytoarchitecture appear to be undisturbed. F, The next successive section of the hair in E shows that the EMT array has almost completely disappeared. Close to the tip, a few EMTs are present. The vacuole has started to overtake the nucleus. G, Projection of two median scans. The EMT array has decreased in density; EMTs in the vicinity of the nucleus are short and fragmented. $\mathbf{H}$, The next successive section of the hair in $G$ reveals that a thin, tubular extension of the central vacuole is penetrating the subapical plasma. EMTs are present at a low density. A and $\mathrm{B}$, Five minutes after control treatment. $\mathrm{C}$ through $\mathrm{H}$, Five minutes after treatment with $10^{-9} \mathrm{M}$ NF. MTs were decorated with immunocytochemistry and visualized with a confocal laser-scanning microscope in scanning steps of $1 \mu \mathrm{m} ; \mathrm{n}=$ nucleus, $\mathrm{v}=$ vacuole. Magnification is the same in all images. Bar $=10 \mu \mathrm{m}$.
1), whereas EMTs closer to the hair tip remained present (Fig. 1C, E through $\mathrm{H})$. The percentage of root hairs with disturbed EMT array 5 min after NF application was higher than 10 min after NF application (significantly different at the 0.05 level, $P$ $=0.021589$, independent Student's $t$ test analysis). The effect on the EMT array was subtle and could be observed only when a successive sequence of optical sections taken with a confocal laser-scanning microscope (CLSM) was investigated. Although the EMT array or the cytoarchitecture in one section appeared normal (Fig. 1E and G), in the next section, the EMT array was shorter and vacuole extensions penetrated the sub-apex (Fig. 1F and H). To find out whether this was a true effect of NFs and not just medium refreshment or the freeze fixation method, we compared NF-challenged root hairs with control hairs subjected to medium refreshment and freeze fixation. In the latter, only $45 \%$ of the hairs responded with a temporarily disturbed EMT array 5 min after treatment with plant growth medium (Table 1), which was lower than 5 min after NF treatment (significantly different at the 0.05 level, $P=0.010104$ ). Cortical MTs (CMTs) in a tip-growing hair treated with NF were not obviously affected (Fig. 1D) at any time after NF application, and their over-all patterning was similar to control root hairs treated with plant growth medium (PGM).

The temporary and partial shortening of the EMT array in elongating root hairs after NF application could be observed only in single optical planes taken with a CLSM from immunolabeled root hairs after freeze fixation and freeze substitution, but not in GFP-MBD-expressing root hairs. This could be due to a lack in resolving power (number and optical depth of $\mathrm{z}$ scans) of the applied imaging technique to observe GFPMBD-decorated MTs in living root hairs (Sieberer et al. 2002), and the fact that the MTs in the living hairs, especially the EMTs, are highly dynamic (Sieberer et al. 2002; Vos et al. 2003) (A. C. J. Timmers, unpublished results), which makes it difficult to visualize their precise configuration in a still image of the dense, three-dimensional EMT array in a tip-growing root hair.

Together with the temporary shortening of the subapical EMT array after NF treatment went a transient vacuolization of the cytoplasmically dense subapical region in elongating root hairs. Within 5 min after NF application in approximately $80 \%$ of the observed hairs, extensions from the central vacuole temporarily entered the dense subapical cytoplasm (Fig 2B). Tip growth did not stop during the temporary disturbance of the subapical region caused by NFs and the cytoarchitecture recovered within 10 to 15 min (Fig. 2C). Further, we compared the cytoarchitecture of tip-growing $M$. truncatula root hairs treated with NF with those treated with oryzalin, an MTdepolymerizing drug. Also, in tip-growing hairs treated with 1 $\mu \mathrm{M}$ oryzalin, thin extensions of the central vacuole started

Table 1. Short-term effects of $10^{-9} \mathrm{M}$ Nod factor (NF) and plant growth medium (PGM) refreshment on the endoplasmic microtubule (EMT) array of tip-growing root hairs ${ }^{\mathrm{a}}$

\begin{tabular}{lll}
\hline & \multicolumn{2}{c}{$\begin{array}{c}\text { \% with temporarily } \\
\text { disturbed EMT array (SD) }\end{array}$} \\
\cline { 2 - 3 } Time after treatment & NF & PGM \\
\hline $5 \mathrm{~min}$ & $76.5(2.12)$ & $45(2.83)$ \\
$10 \mathrm{~min}$ & $33.5(4.95)$ & $31(2.83)$ \\
$30 \mathrm{~min}$ & $27(1.41)$ & $23.5(2.12)$ \\
\hline
\end{tabular}

a Samples were cryofixed 5, 10, and 30 min after NF treatment. EMTs were labeled with immunocytochemistry and visualized with confocal laser scanning microscopy. In all, 40 root hairs per time point (four different roots, 10 hairs per root) for each treatment were observed. The number of root hairs with disturbed EMT arrays was scored. The results are presented as the mean percentages with standard deviation (SD) of two independent repeats of the experiment. 
penetrating the dense cytoplasm within 5 min after application (Fig. 2E). In contrast to NF-treated hairs, these vacuolar extensions increased in volume until the dense cytoplasm in the subapex had completely disappeared within 10 to $20 \mathrm{~min}$, except for a cortical layer in the hair tube and a smooth, vesiclerich region at the very tip of the hair (Fig. 2F). In the presence of oryzalin, the subapical dense cytoplasm and the EMT array never recovered in elongating hairs, and tip-growth proceeded, though at a lower growth rate (Sieberer et al. 2002). Control medium refreshment did not affect, or only slightly affected, the subapical cytoarchitecture of tip-growing hairs (Fig. 2G through I).

\section{Effects of NF on the MT cytoskeleton} and the cytoarchitecture of growth-arresting root hairs.

The observed changes in the MT cytoskeleton in elongating root hairs upon NF treatment were subtle and short termed; therefore, we studied the MTs in growth-arresting hairs after NF application as well. In contrast to younger tip-growing hairs, growth-arresting hairs respond to globally applied NF with a distinct change in hair morphology called "root hair deformation." Several cellular responses of the initial effects of NFs can be elucidated by studying root hair deformation (Lhuissier et al. 2001), allowing the researcher more black and white evaluation of the pronounced cellular responses to NFs, which in our case are NF-induced changes of the MT cytoskeleton.

During growth arrest, the EMT array gradually shortens as the dense cytoplasm in the subapex decreases in length and eventually disappears after growth termination (Sieberer et al. 2002). However, as long as tip growth continues, EMTs are present. We have defined growth arrest as the time between the moment the vacuole permanently overtakes the nucleus and stop of hair elongation (Sieberer and Emons 2000). This process can take as long as 2 to $3 \mathrm{~h}$.

Upon application of $10^{-9} \mathrm{M} \mathrm{NF}$, the short EMT array of a growth-arresting hair disappeared within 5 to $10 \mathrm{~min}$ (Fig 3). At 20 to $30 \mathrm{~min}$ later, subapical EMTs reappeared inside a single or multiple transvacuolar cytoplasmic strand or strands (Fig. 3C and D). During root hair tip swelling, these cytoplasmic strands were constantly changing shape and volume, and, depending on their volume, contained various amounts of EMTs (Fig. 4A, B, and E). CMTs were extending to and reaching the very tip of growth-arresting hairs within 5 to $10 \mathrm{~min}$ after NF application. This usually is a sign that tip growth is ceasing (Sieberer et al. 2002); however, in
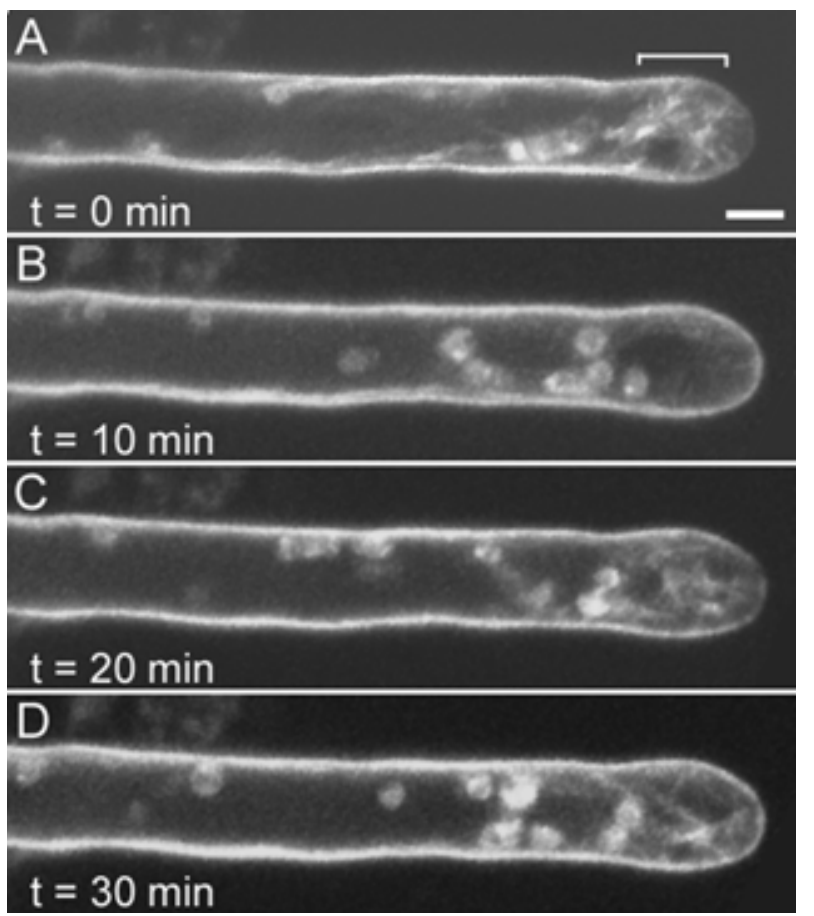

Fig. 3. Time series of endoplasmic microtubules (EMTs) in a growtharresting Medicago truncatula root hair treated with $10^{-9} \mathrm{M}$ Nod factor. Microtubules (MTs) were decorated with green-fluorescent protein MT binding domain and visualized with a confocal laser-scanning microscope in scanning steps of $1 \mu \mathrm{m}$; for each image, three median sections were projected. Magnification is the same in all images. Bar $=10 \mu \mathrm{m}$. A, Before treatment; in the subapex there still is a short EMT array present (bracket). B, Ten minutes after treatment. The EMT array has disappeared. C, Twenty minutes after treatment. Single EMTs have reappeared inside a cytoplasmic strand in the sub-apex of the hair. D, Thirty minutes after treatment. EMTs within transvacuolar cytoplasmic strands have increased in density, but a dense EMT array as seen in A has not yet been rebuilt.
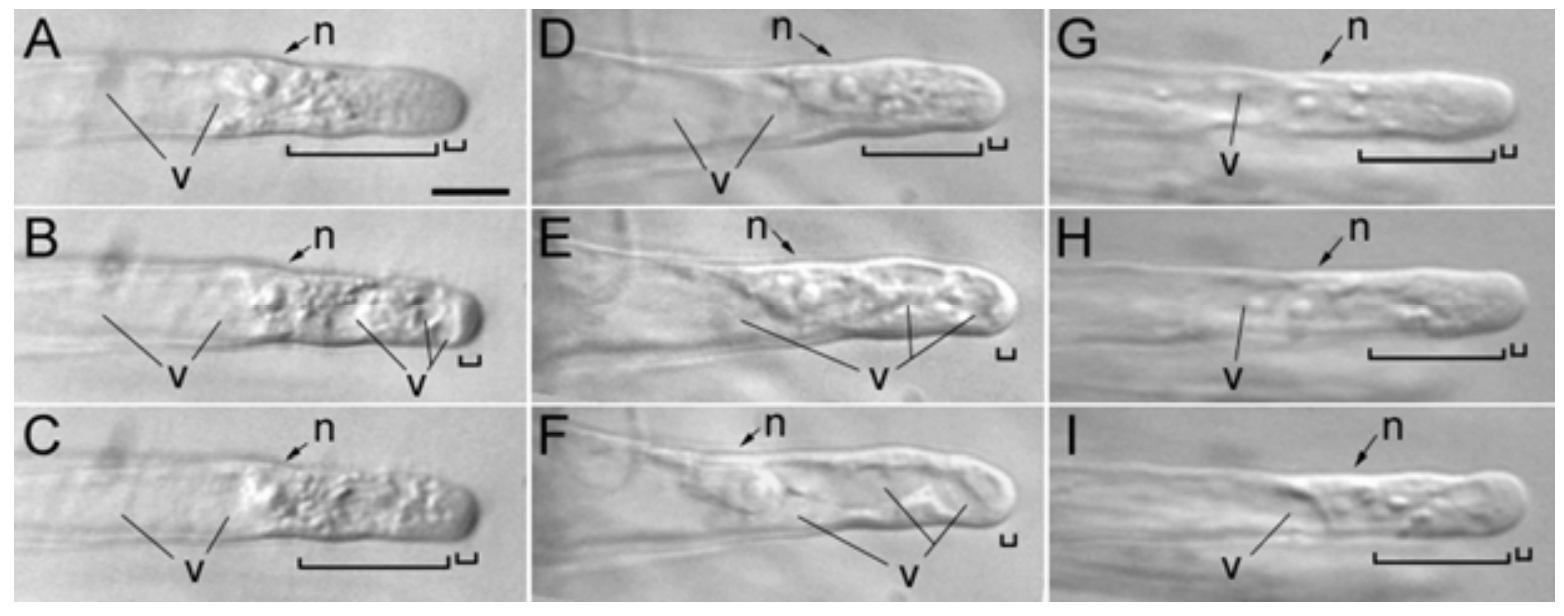

Fig. 2. Short-term effect of $10^{-9} \mathrm{M}$ Nod factor (NF), $1 \mu \mathrm{M}$ oryzalin, and medium refreshment on the cytoarchitecture of tip-growing Medicago truncatula root hairs. Time series of living root hairs obtained with bright-field microscopy. Large bracket indicates the subapical region rich in cytoplasm; small bracket indicates the clear zone (vesicle-rich region); $\mathrm{n}=$ nucleus, $\mathrm{v}=$ vacuole. Magnification is the same in all images. Bar $=20 \mu \mathrm{m}$. A, Before treatment. B, Five minutes after NF. The subapical cytoarchitecture is heavily disturbed. C, Fifteen minutes after NF. The cytoarchitecture has almost completely recovered. D, Before treatment. E, Five minutes after oryzalin. The subapical cytoarchitecture is heavily disturbed. F, Fifteen minutes after oryzalin. Except for the vesicle-rich region at the very tip, the vacuole almost completely fills the subapex. In the presence of oryzalin, the cytoarchitecture is not recovering. G, Before treatment. H, Five minutes after medium refreshment. I, Fifteen minutes after medium refreshment. 
contrast to a fully grown hair, CMT density did not decrease over time (Fig. 4C and D) and CMTs did not converge at the root hair tip (Fig. 5A compared with B) after NF application. As expected, in growth-arresting hairs the prime effect of NFs on MTs was a rapid shortening of EMTs, whereas CMTs were affected to a lesser extent or not at all.

A new root hair outgrowth emerged from the swollen tip between 90 to 120 min after application of NF. The dense threedimensional EMT array described for a tip-growing root hair progressively reappeared (Fig. 6) and the newly formed outgrowth had a polarized cytoarchitecture (Fig. 7D). Once tipgrowth had reinitiated, the very tip of the newly formed outgrowth was devoid of detectable CMTs (Fig. 6A through D), the same situation as in a tip-growing root hair (Sieberer et al. 2002) (Fig. 1A). Cellular responses of growth-arresting hairs to NF application are summarized in Table 2.

Oryzalin in a concentration of $10 \mu \mathrm{M}$ has been reported to cause bulging and branching of alfalfa root hairs (Weerasinghe et al. 2003). In growth-arresting root hairs that respond to NF with root hair deformation, we found that $1 \mu \mathrm{M}$ oryzalin triggered swelling and outgrowth of root hair tips in a similar fashion as do NFs (see below). Therefore, we compared the effect of $1 \mu \mathrm{M}$ oryzalin on the MT cytoskeleton in hairs of this developmental stage with the effect of NF. In growth-arresting hairs treated with $1 \mu \mathrm{M}$ oryzalin, EMTs did not reappear during root hair swelling at any time after treatment (Fig. 5D and F). Further, no EMTs were found in the subapex of the outgrowth that emerged from the oryzalin-induced swelling (data not shown). CMTs did not converge at the very tip of the hair, but appeared to be fragmented (Fig. 5C and E). CMTs in the shank of the hairs were not obviously affected by $1 \mu \mathrm{M}$ oryzalin (Fig. 5C and E). They also remained present in the
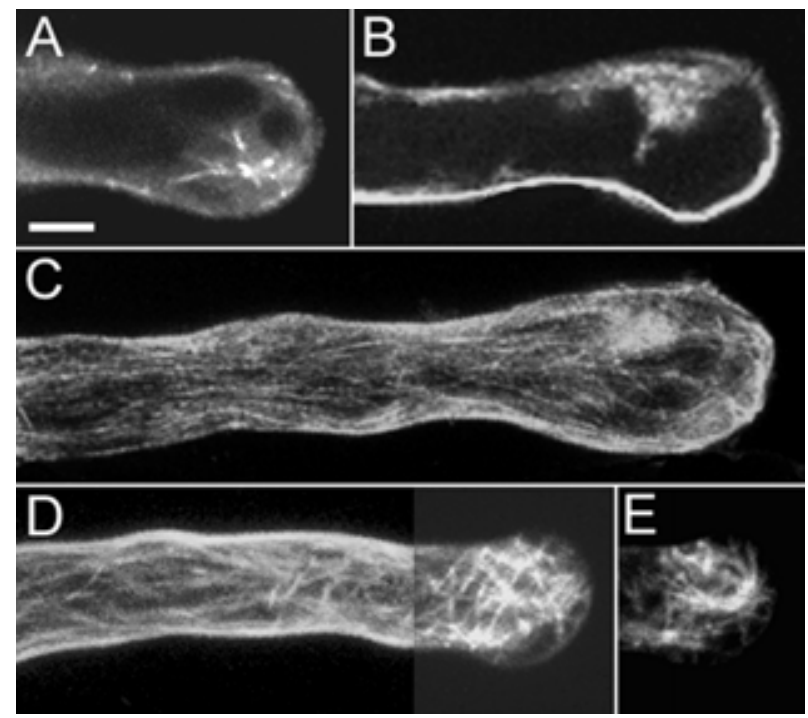

Fig. 4. Microtubules (MTs) in the swellings of growth-arresting root hairs treated with $10^{-9} \mathrm{M}$ Nod factor (NF). MTs where visualized with confocal laser-scanning microscope in scanning steps of $1 \mu \mathrm{m}$. Magnification is the same in all images. Bar $=20 \mu \mathrm{m}$. A, Sixty minutes after NF; projection of two median sections shows endoplasmic MTs (EMTs) inside the swelling. B, Seventy minutes after NF; projection of two median sections shows EMTs inside the swelling. EMTs are located in cytoplasmic strands that constantly change shape, size, and orientation. C, Seventy minutes after NF; full-stack projection shows that CMTs remain present in a high density. D, Seventy minutes after NF; full-stack projection shows CMTs in a high density and a net-axial orientation in the shank of the hair and in a random pattern in the swelling. E, A projection of three median sections of the hair in D shows that EMTs appear in different densities within cytoplasmic strands inside the swelling. A through C, Immunocytochemistry; D and E, green-fluorescent protein MT binding domain. swelling, but were completely absent in the newly formed outgrowth (data not shown). Thus, although NF and oryzalin both induced swelling and outgrowth, the behavior of the MT cytoskeleton was different.

\section{MTs determine the angle}

with which the new outgrowth deviates

from the former growth axis during root hair deformation.

After application of $10^{-9} \mathrm{M} \mathrm{NF}$, growth-arresting hairs responded within minutes and their tips started to swell. Between 90 and $120 \mathrm{~min}$ after NF application, a tip-growing tube reinitiated from the swelling. It is important to note that NF-treated growth-arresting root hairs can become longer than control root hairs (Sieberer and Emons 2000). The newly formed outgrowth had a fully recovered polarized cytoarchitecture similar to a young tip-growing hair with a smooth, vesicle-rich region at the very tip, a tip-nucleus distance of 30 to $40 \mu \mathrm{m}$, and accumulated cytoplasm in the subapex (Fig. 7A compared with D). On average, the growth axis of the newly formed outgrowth deviated from the original growth axis of the hair by $23.3^{\circ}$ (Table 3 ).

The tips of elongating $M$. truncatula root hairs swelled after treatment with low concentrations of actin-depolymerizing drugs and subsequent recovery of tip-growth occurred in the original growth orientation (Fig. 7B and C; Table 3) which, in the case of cytochalasin $\mathrm{D}$, was significantly different at the 0.05 level from NF $(P<0.01)$ or oryzalin-induced growth reorientation $(P<0.01)$ (independent Student's $t$ test analysis).

Oryzalin had an effect on the morphogenesis of a growtharresting hair similar to NF. After root hair swelling, a new outgrowth formed between 90 and $120 \mathrm{~min}$ after application of $1 \mu \mathrm{M}$ oryzalin. The newly formed outgrowth deviated by $29.5^{\circ}$, on average, from the original growth orientation of the hair (Fig. 7E; Table 3), which was similar to NF-induced growth deviation (not significantly different at the 0.05 level, $P=0.102237184$ ). However, in oryzalin-treated hairs, the newly formed outgrowth did not regain the same cytoarchitecture as in NF-treated hairs. The tip region contained a thin layer of cytoplasm (Fig. 7E, small bracket), no dense cytoplasm accumulated in the subapex, and the nucleus did not obtain a distance to the tip of 30 to $40 \mu \mathrm{m}$ (Fig. 7A compared with $\mathrm{D}$ and $\mathrm{E})$. Indeed, oryzalin-treated growth-arresting hairs did not get new growth potential but, instead, stopped elongating at, or before, the time and length normal for the species (data not shown).

When a combination of $10^{-9} \mathrm{M}$ NF and $1 \mu \mathrm{M}$ oryzalin was applied to growth-arresting hairs, the hair tips formed a swelling. A new outgrowth emerged from the swelling between 90 and 120 min after application (Fig. 7F). However, the polarized cytoarchitecture was not restored, which was the same after oryzalin treatment alone. The subapex in such hairs was devoid of dense cytoplasm (Fig. 7A compared with D and F). Interestingly, the newly formed outgrowth deviated, with a steeper angle of $68.5^{\circ}$ (Table 3) on average, from the original growth axis of the hair compared with the outgrowth of hairs treated with either $1 \mu \mathrm{M}$ oryzalin (significantly different at the 0.05 level, $P<$ 0.01 ) or NF alone (significantly different at the 0.05 level, $P<$ 0.01 ) (Table 3 ). The effects of NF and $1 \mu \mathrm{M}$ oryzalin were additive, showing that the (partial) impairment of MTs leads to an increase of the angle at which the newly formed outgrowth deviates from the original growth axis.

When oryzalin was applied within $60 \mathrm{~min}$ to hairs initially treated with NF only, the deviation of the outgrowth was similar to that of hairs exposed to a combination of $\mathrm{NF}$ and oryzalin, whereas an application of oryzalin later than $60 \mathrm{~min}$ after NF treatment caused a deviation similar to that of NF alone (data not shown). 
These findings indicate that MTs serve in determining growth directionality of $M$. truncatula hairs. This was exemplified further by the approximately $12 \%$ of root hairs that showed problems with restricting tip growth to only one site (Fig. 7G). To learn whether MTs have to be dynamic for NF to alter them such that the directionality of root hair elongation changes, we applied NF to root hairs in which the MTs were stabilized with taxol.

In growth-arresting root hairs treated with a combination of $10^{-9} \mathrm{M} \mathrm{NF}$ and $1 \mu \mathrm{M}$ taxol, tip growth ceased within minutes of application and hair tips started to swell. Tip growth reinitiated between 90 to $120 \mathrm{~min}$ after application. The newly formed outgrowth deviated with a smaller angle of approximately $16.4^{\circ} \mathrm{C}$ from the original growth axis (Fig. 7H; Table 3) when compared with NF (significantly different at the 0.05 level, $P<0.01)$, oryzalin $(P<0.01)$, or a combination of NF and oryzalin $(P<0.01)$. Taxol alone did not cause changes in root hair morphology, but did slow elongation speed (Sieberer et al. 2002).
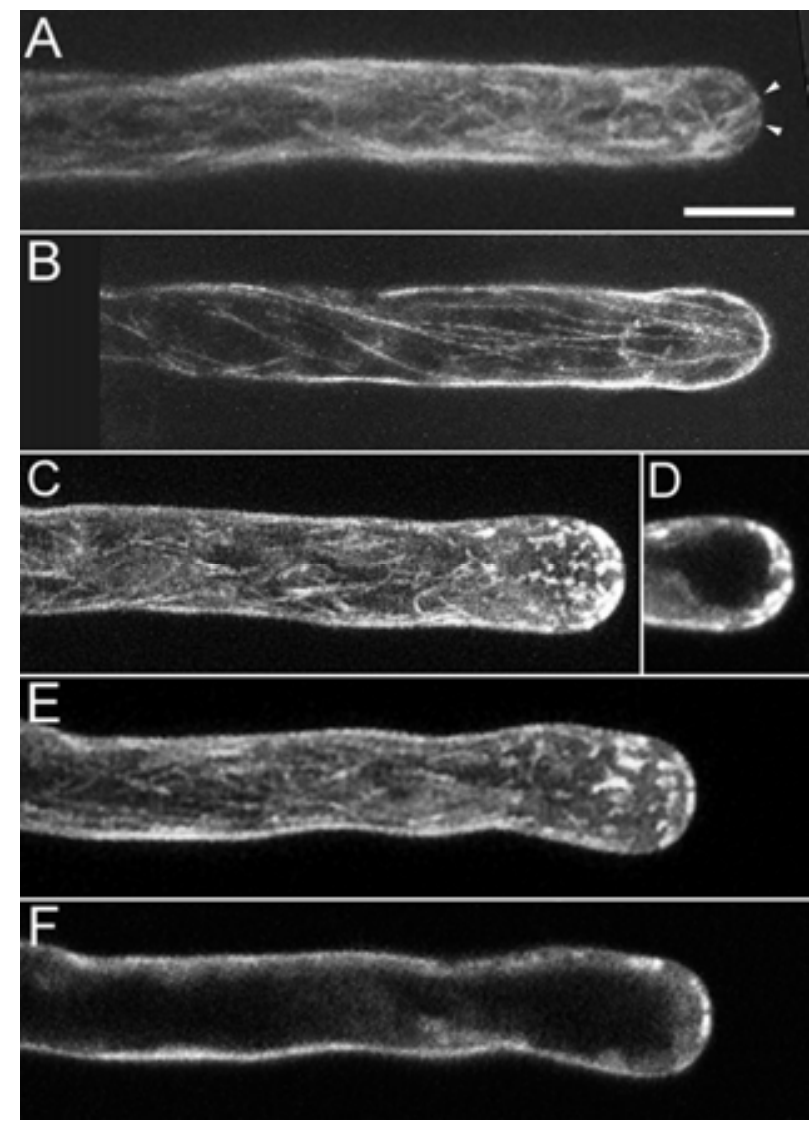

Fig. 5. Microtubules (MTs) in a growth-arresting hair treated with $10^{-9} \mathrm{M}$ Nod factor (NF), in a fully grown hair, and in a growth-arresting hair treated with $1 \mu \mathrm{M}$ oryzalin. Magnification is the same in all images. Bar = $20 \mu \mathrm{m}$. A, Twenty-five minutes after NF; full-stack projection. Cortical MTs (CMTs) appear in the very tip (arrowheads), but do not converge. In the shank, CMTs remain present in a high density (compare with B). B, Fully grown hair; full-stack projection. CMTs have decreased in density. The subapex is devoid of endoplasmic MTs (EMTs). C, Thirty minutes after oryzalin. In a full-stack projection, CMTs appear fragmented in the hair tip. D, Projection of two median sections of the hair in C shows that EMTs have completely disappeared. E, Sixty minutes after oryzalin. Fullstack projection shows that, in the swelling, the tip region still is devoid of a CMT array; CMTs in the shank remain present. F, Projection of two median sections of the hair in E shows that EMTs are completely absent in the swelling. A and C through F, Green-fluorescent protein MT binding domain; B, immunocytochemistry.

\section{DISCUSSION}

Endoplasmic MTs are a target for NF signaling and involved in NF-induced root hair reorientation.

Our study shows that treatment with NF causes a rapid, subtle, and transient shortening of the subapical EMT array in tipgrowing $M$. truncatula root hairs. The effect of NF on the EMTs is more severe than on CMTs. The short EMT array of growtharresting hairs completely disappeared after NF application, but started to reappear after 20 to $30 \mathrm{~min}$, after which growth resumed, albeit in a different orientation. This deviation of the new outgrowth from the original growth axis was larger when NF and the MT-depolymerizing drug oryzalin were applied together and smaller when NF was applied in combination with taxol, a MT-stabilizing drug. In addition, the oryzalin-induced absence of EMTs, as well as their stabilization by taxol, suppressed the NF-induced new growth potential in growth-arresting hairs. Together, these findings demonstrate that the MT cytoskeleton contributes to the tip-growth process and to the determination of growth direction of elongating hairs, and that it is a direct or indirect target of early NF signaling. The latter two features are crucial for root hair curling around rhizobia.

Our results on changes of the MT cytoskeleton in root hairs after NF challenge differ substantially from those reported by Weerasinghe and associates (2003). These authors describe a complete disintegration of the MT cytoskeleton in elongating $M$. sativa root hairs after NF perfusion, starting at the base of the hair within 3 min with the EMTs and within 10 min with the CMTs. The disintegration of the CMTs was completed within $30 \mathrm{~min}$. The MT network reformed $60 \mathrm{~min}$ after NF exposure although, in hairs longer than 150 to $180 \mu \mathrm{m}$, the recovery was incomplete. In $M$. truncatula root hairs, we never observed such a dramatic change in MT organization at any time
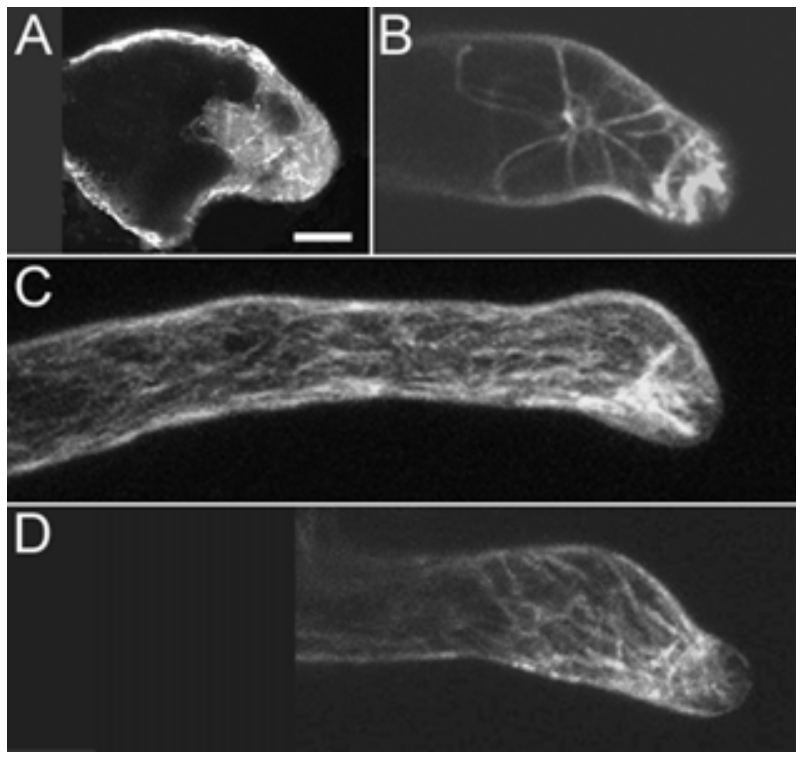

Fig. 6. Microtubules (MTs) in the newly formed outgrowth after application of $10^{-9} \mathrm{M}$ Nod factor (NF) to growth-arresting Medicago truncatula root hairs. A, Immunocytochemistry; $\mathbf{B}$ through $\mathbf{D}$, green-fluorescent protein MT binding domain. Magnification is the same in all images. Bar $=10$ $\mu \mathrm{m}$. A, At $120 \mathrm{~min}$ after NF; projection of two median sections shows endoplasmic MTs (EMTs) in the emerging outgrowth. B, At $150 \mathrm{~min}$ after $\mathrm{NF}$; projection of two median sections shows EMTs in the subapex of the newly formed outgrowth. EMTs are located inside cytoplasmic strands. C, At 120 min after NF; full-stack projection shows a dense EMT array in the subapex of the outgrowth. In the shank and in the swelling, CMTs are netaxially oriented. The very tip of the outgrowth is devoid of detectable MTs. D, At $150 \mathrm{~min}$ after NF; full-stack projection. The MT array has been almost completely rebuilt. 
after NF application. Species-specific differences in the NF response of MTs may explain the different observations made in $M$. sativa and $M$. truncatula, but they are not very likely, because the organization of the MT cytoskeleton in elongating root hairs and the pattern of root hair deformation after NF application appear to be similar in the two species (Weerasinghe et al. 2003; this article). The different method of NF application used by Weerasinghe and associates (2003) or a not fully optimized chemical fixation protocol could be the reason for the dissimilar results. Gentle application of NF was described to be crucial for an undisturbed cytoarchitecture of root hairs (Esseling et al. 2004) and, thus, the cytoskeleton. Further, it has been shown that a not-optimized chemical fixation can cause severe artifacts of the actin cytoskeleton-and, hence, the
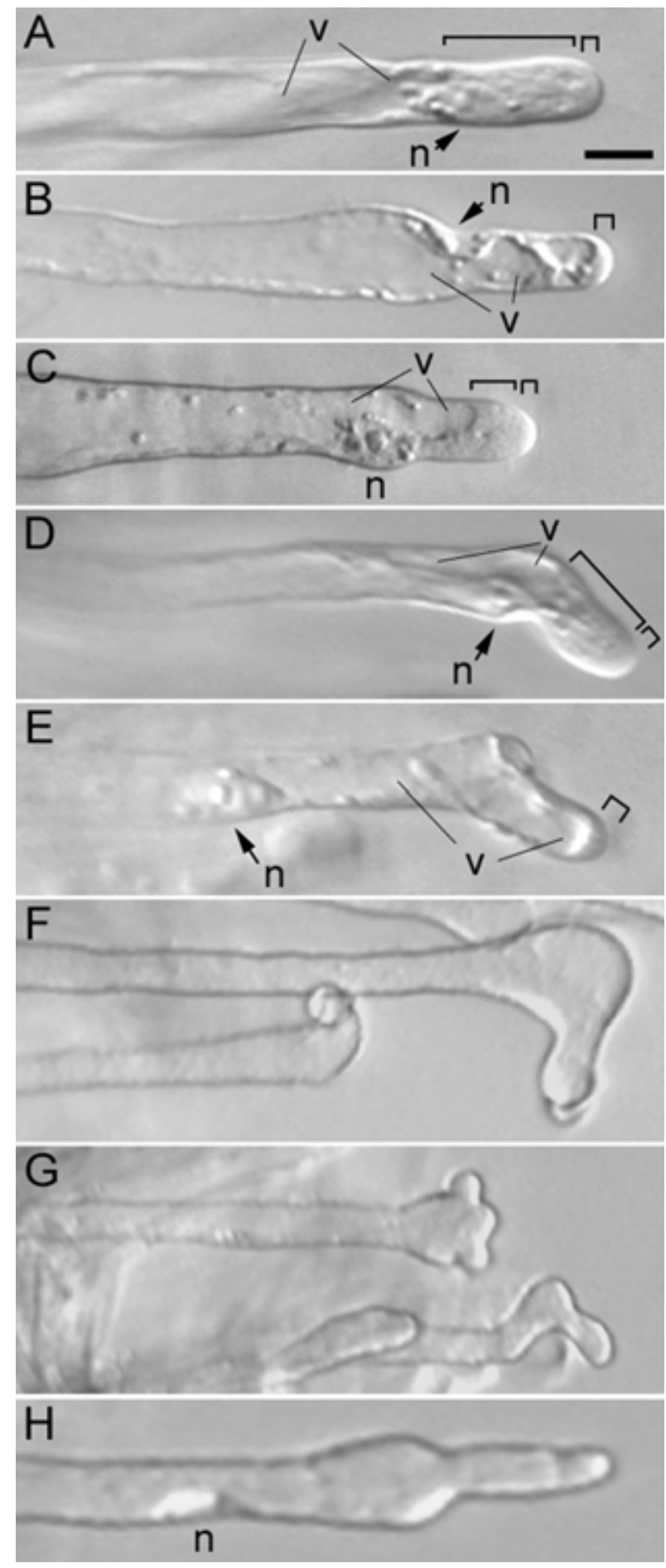

cytoarchitecture - in root hairs (Esseling et al. 2000; Ketelaar and Emons 2001) and pollen tubes (Lovy-Wheeler et al. 2005), reasons why we used freeze fixation and GFP technology.

The subtle changes in the MT pattern after NF treatment that we report here could point toward a transient change in the dynamic instability parameters of EMTs. In tip-growing $M$. truncatula root hairs, EMTs are highly dynamic (Vos et al. 2003) and more sensitive to MT depolymerizing drugs than CMTs (Sieberer et al. 2002), which could explain why EMTs are more severely affected by NF than CMTs. An NF-induced increase in MT dynamic instability parameters could be a prerequisite for the changes in the MT cytoskeleton that are needed to redirect root hair growth for obtaining root hair curling around rhizobia. Measurements of MT dynamic instability parameters have been performed successfully in the plant cell cortex (Donukshe and Gadella 2003; Shaw et al. 2003; Vos et al. 2004), including the cortex of Arabidopsis root hairs (Van Bruaene et al. 2004). In the large volume of the subapex of $M$. truncatula root hairs with its dense EMT array, analysis of the behavior of individual MTs was impossible to carry out with current methods. As often is the case in cell biology, new instrumentation should bring further answers.

The question arises of how the dynamic instability could be altered by NF. MT depolymerization can be triggered, for instance, by increased cytoplasmic calcium levels (Cyr 1991, 1994). Elongating root hairs have a tip-focused $\mathrm{Ca}^{2+}$ gradient, which increases in legumes within minutes after application of NF (Allen et al. 1994; Cárdenas et al. 1998; De Ruijter et al. 1998; Felle et al. 1998, 1999a,b), leading to several downstream events affecting the cytoskeleton (Lhuissier et al. 2001). The Arabidopsis ton mutant has high calcium-channel activity and constitutively disorganized CMTs (Thion et al 1998). These findings could imply that NF influences the MT organization in the root hair tip of legumes via transiently increased calcium levels.

\section{The effect of NF \\ on the MT cytoskeleton differs from that of oryzalin.}

The effect of oryzalin on MTs partly resembles the effect of NF: in both cases, the EMT array shortens. Further, NF and oryzalin cause a similar deformation phenotype in growtharresting hairs and, when applied together, they have an addi-

Fig. 7. Root hair deformation of growth-arresting root hairs after treatment with actin inhibitors, Nod factor (NF), or microtubule inhibitors. Bright-field images of living root hairs. Large bracket indicates the subapical region that is rich in cytoplasm; small bracket indicates the smooth (vesicle-rich) region; $\mathrm{n}=$ nucleus, $\mathrm{v}=$ vacuole. Magnification is the same in all images. Bar $=20$ $\mu \mathrm{m}$. A, At $60 \mathrm{~min}$ after growth medium refreshment, showing undisturbed tip-growth pattern B, At 60 min after recovery from a 45 -min pulse treatment with $1 \mu \mathrm{M}$ cytochalasin $\mathrm{D}$; the newly formed outgrowth shows no deviation from the original growth. C, At $60 \mathrm{~min}$ after recovery from a 45-min pulse treatment with $10 \mathrm{nM}$ latrunculin; the newly formed outgrowth shows no deviation from the original growth axis. D, At $120 \mathrm{~min}$ after $10^{-9} \mathrm{M} \mathrm{NF}$; the newly formed outgrowth deviates by approximately $35^{\circ}$ from the original growth axis and has a similar cytoarchitecture as a tip-growing hair. E, At $180 \mathrm{~min}$ after $1 \mu \mathrm{M}$ oryzalin; the newly formed outgrowth deviates by approximately $36^{\circ}$ from the original growth axis and has not regained the cytoarchitecture of a tip-growing root hair. F, At $140 \mathrm{~min}$ after a combination of $10^{-9} \mathrm{M} \mathrm{NF}$ and $1 \mu \mathrm{M}$ oryzalin; the newly formed outgrowth deviates by approximately $100^{\circ}$ from the original growth axis and has not regained the polar cytoarchitecture of a tip-growing root hair. G, Same treatment as in F; some of the hairs had problems with restricting tip growth to one site (upper hair) or with maintaining one growth directionality (lower hair). Root hairs have not regained the polar cytoarchitecture of tip-growing hairs. H, At 140 min after a combination of $10^{-9} \mathrm{M} \mathrm{NF}$ and $1 \mu \mathrm{M}$ taxol; the newly formed outgrowth shows no deviation from the original growth axis and has not regained the polar cytoarchitecture of a tip-growing hair. 
tive effect on root hair deformation. This indicates that, although both NF and oryzalin cause depolymerization of EMTs, their mode of action is different. If NF had the same mode of action on MTs as oryzalin, a higher concentration of NF or oryzalin alone should lead to a similar deformation phenotype as a combination of NF and oryzalin. This is not the case (data not shown). Oryzalin binds to tubulin heterodimers, preventing further growth of MTs, which eventually leads to MT depolymerization as long as oryzalin is present (Anthony and Hussey 1999). The action mechanism of NF on MTs is unknown. The most important difference between NF and oryzalin is the fact that EMTs start to reappear in an NF-treated hair, eventually forming a dense three-dimensional EMT array in the subapex of the new outgrowth.

\section{MTs and actin filaments are early targets of NF signaling.}

Recovery of tip growth in $M$. truncatula root hairs from actin-depolymerizing drugs after tip swelling takes place in the original orientation of hair elongation (Fig. 7B and C). The same has been observed in Arabidopsis thaliana root hairs that were treated with F-actin-depolymerizing drugs (Ketelaar et al. 2003). In terms of root hair morphogenesis, NF-induced root hair deformation resembles hair deformation after MT depolymerization by oryzalin and not after fine F-actin depolymerization. The NF-induced deformation phenotype in $M$. truncatula root hairs can be mimicked in A. thaliana by a pulse treatment with F-actin-depolymerizing drugs in root hairs where MTs were experimentally ablated (Ketelaar et al. 2003). Thus, it can be concluded that, in addition to a signaling pathway toward the actin cytoskeleton ( $V$. sativa [De Ruijter et al. 1999; Ridge 1992], M. sativa [Allen et al. 1994] and P. vulgaris [Cárdenas et al. 1998, 2003]), NF induces a signal transduction pathway toward MTs. If NF would signal only toward the actin cytoskeleton, the newly formed outgrowth in an NF-challenged hair should occur in the same direction as after treatment with actin-depolymerizing drugs; that is, without a deviation from the original growth axis. This clearly is not the case.

From our results, it cannot be concluded whether either MTs or actin filaments are the prime target of NF signaling, whether one of the two cytoskeleton compounds influences the other, or whether they respond simultaneously to NF. Even though the importance of the actin cytoskeleton in NF signaling is paramount, we have demonstrated that the MT component of the cytoskeleton also is essential for setting up the interaction between rhizobia bacteria and legumes.

\section{MATERIALS AND METHODS}

\section{Plant transformation with GFP-MBD.}

The GFP-MBD fusion gene, linked to an upstream 35S promoter, was provided in a pUC18 vector by R. Cyr (Marc et al.
1998). The complete insert from this plasmid was transferred to pCambia1390 (CAMBIA, Canberra, Australia; provided by T. W. J. Gadella, Jr. (University of Amsterdam, The Netherlands), by using the HindIII-EcoRI sites. Transformed roots of M. truncatula cv. Jemalong were obtained by using Agrobacterium rhizogenes according to the protocol described by BoissonDernier and associates (2001).

\section{Plant culture.}

Seed of M. truncatula cv. Jemalong (Fabaceae) were germinated as described previously (Sieberer et al. 2002). For live observation and immunocytochemistry of wild-type root hairs after NF or drug treatment, seedlings were grown at an angle of approximately $25^{\circ} \mathrm{C}$ for 24 to $30 \mathrm{~h}$ between a cover slip and a glass slide (Fåhraeus slides) (Fåhraeus 1957; Heidstra et al. 1994) in sterile conditions at $24^{\circ} \mathrm{C}$ with a 16 -h day length. The space between cover slip and glass slide was $1.2 \mathrm{~mm}$. Each of these microchambers contained two seedlings and $2.4 \mathrm{ml}$ of PGM (1.36 mM CaCl $2,0.97 \mathrm{mM} \mathrm{MgSO} 4,1.12 \mathrm{mM} \mathrm{Na}_{2} \mathrm{PO}_{4}$, $1.36 \mathrm{mM} \mathrm{KH}_{2} \mathrm{PO}_{4}$, and $20 \mu \mathrm{M}$ Fe-citrate, $\mathrm{pH}$ 6.5). The plants with transgenic roots were transferred 3 to 4 weeks after transformation into square, 12-cm plastic dishes (Greiner Labortechnik, Kremsmünster, Austria) with a round perforation of approximately $5 \mathrm{~mm}$ in diameter in the middle of one of the four sides. Each individual plant was put in the perforation in such a way that the root was inside on PGM containing $0.8 \%$ agar and the stem part was outside the plate. Plates were put vertically in a culture room at $25^{\circ} \mathrm{C}$ with an 18 -h day length.

\section{NF treatment and drug studies.}

Before any treatment, the Fåhraeus slides were placed gently on the microscope stage and plants were left to recover for at least half an hour.

NF (NodRm-IV[C16:2, Ac, S]) was used in a concentration range of $10^{-8}$ to $10^{-11} \mathrm{M}$ in PGM. All concentrations used gave similar results. Presented are results obtained with $10^{-9} \mathrm{M} \mathrm{NF}$, because this concentration was used by us in previous work on M. truncatula root hairs (Esseling et al. 2004; Sieberer and Emons 2000). NF application was done on the stage of the mi-

Table 3. Deviations from the original growth axis of root hairs after 180 min of Nod factor (NF) or cytoskeleton inhibitor treatment ${ }^{\mathrm{a}}$

\begin{tabular}{lc}
\hline Treatment & Deviation in degrees (SD) \\
\hline $1 \mu \mathrm{M}$ cytochalasin D & $15.8(14.9)$ \\
$10^{-9} \mathrm{M} \mathrm{NF}$ & $23.3(18.4)$ \\
$1 \mu \mathrm{M}$ oryzalin & $29.5(14.2)$ \\
$10^{-9} \mathrm{M} \mathrm{NF}+1 \mu \mathrm{M}$ oryzalin & $68.5(20.8)$ \\
$10^{-9} \mathrm{M} \mathrm{NF}+1 \mu \mathrm{M}$ taxol & $16.4(13.1)$ \\
\hline
\end{tabular}

${ }^{a}$ Values are averages of 40 hairs with their standard deviation (SD). Three independent replicates for each treatment were performed.

Table 2. Nod factor (NF) effects on growth-arresting Medicago truncatula root hairs

\begin{tabular}{|c|c|c|c|}
\hline Effects $^{a}$ & Growth-arresting root hairs & Fully grown root hairs & Effects of treatment on growth-arresting root hairs ${ }^{b}$ \\
\hline Tip growth & $\begin{array}{l}\text { Gradually decreasing growth rate } \\
\text { until growth stops }\end{array}$ & No cell elongation & $\begin{array}{l}\text { Tip growth switches to isodiametric growth within } \\
5 \text { min; reinitiates within } 90 \text { to } 120 \mathrm{~min}\end{array}$ \\
\hline Dense cytoplasm in subapex & $\begin{array}{l}\text { Gradually shortening until } \\
\text { disappearance at growth-arrest }\end{array}$ & Absent & $\begin{array}{l}\text { Disappearance within } 5 \text { min; reappearance within } \\
90 \text { to } 120 \mathrm{~min}\end{array}$ \\
\hline EMT array & $\begin{array}{l}\text { Gradually shortening until } \\
\text { disappearance at growth-termination }\end{array}$ & Absent & $\begin{array}{l}\text { Disappears within } 5 \text { min; reappears in transvacuolar } \\
\text { cytoplasmic strands within } 20 \text { to } 30 \mathrm{~min}\end{array}$ \\
\hline CMTs & $\begin{array}{l}\text { Start reaching the hair tip; net-axially } \\
\text { aligned. }\end{array}$ & $\begin{array}{l}\text { Converge at hair tip; low } \\
\text { density; net-axially } \\
\text { aligned }\end{array}$ & $\begin{array}{l}\text { Single CMTs reach the hair tip; high density; net-axially } \\
\text { aligned in hair tube; randomly aligned in swelling }\end{array}$ \\
\hline Distance nucleus tip & Gradually increasing & $\begin{array}{l}\text { Random position in } \\
\text { root hair }\end{array}$ & $\begin{array}{l}\text { Larger than } 30 \text { to } 40 \mu \mathrm{m} \text { for } 60 \mathrm{~min} \text {; distance of } 30 \text { to } \\
40 \mu \mathrm{m} \text { from tip in new outgrowth }\end{array}$ \\
\hline
\end{tabular}

\footnotetext{
${ }^{\mathrm{a}} \mathrm{EMT}=$ endoplasmic microtubule, $\mathrm{CMT}=$ cortical microtubule.
}

${ }^{\mathrm{b}}$ Effects of treatment with $10^{-9} \mathrm{M} \mathrm{NF}$. 
croscope at room temperature in Fåhraeus slides with a constant flow of $800 \mu \mathrm{min}^{-1}$, gradually replacing the PGM in the slides. The final volume in each slide was $2.4 \mathrm{ml}$. For rapid freeze fixation, roots were taken out of the Fåhraeus slides 5, 10, 20, 30, 70, and $120 \mathrm{~min}$ after NF application and within 2 to $3 \mathrm{~s}$ directly plunged into liquid propane.

Oryzalin (Greyhound Chromatography, Birkenhead, U.K.) was dissolved in dimethyl sulfoxide (DMSO; Merck, Darmstadt, Germany) as $10 \mathrm{mM}$ stock solution and used at $1 \mu \mathrm{M}$ in PGM. Taxol (paclitaxel; Sigma-Aldrich Chemie B.V., Zwijndrecht, The Netherlands) was dissolved in DMSO as $10 \mathrm{mM}$ stock solution and used at $1 \mu \mathrm{M}$ in PGM.

For combination treatments of NF and MT inhibitors the final concentrations were $10^{-9} \mathrm{M} \mathrm{NF}$ and $1 \mu \mathrm{M}$ oryzalin, or $10^{-9} \mathrm{M}$ $\mathrm{NF}$ and $1 \mu \mathrm{M}$ taxol in PGM.

In Fåhraeus slides, drug solutions or a combination of NF and drugs were applied on the microscope stage with a constant flow of $800 \mu \mathrm{min}^{-1}$, gradually replacing the PGM in the slides. The total volume washed through each slide was $2.4 \mathrm{ml}$. The drug- or NF-induced deviations from the original growth axis were measured in growth-arresting hairs with a length of at least $400 \mu \mathrm{m}$ by the time treatment started.

Drugs were applied to GFP-MBD-expressing root hairs by submerging the roots growing on agar in solutions of $10^{-9} \mathrm{M}$ $\mathrm{NF}$ or $1 \mu \mathrm{M}$ oryzalin in PGM. After submerging, roots were covered with a gas-permeable plastic foil (bioFOLIE 25; Sartorius AG, Vivascience Support Center, Göttingen, Germany) to prevent them from drying, and observed as described below.

\section{Bright-field microscopy.}

Root hairs were observed with a $\times 200.4$ n.a. (numerical aperture) or a $\times 400.55$ n.a. objective (Nikon, Kawasaki, Japan) on an inverted microscope with Hoffman modulation contrast system (DIAPHOT 200; Nikon), equipped with a CCD camera (DXC-95OP; Sony, Tokyo). Image recording and processing were done with a real-time digital contrast and low-light enhancement image processor (ARGUS-20; Hamamatsu Photonics, Hamamatsu City, Japan). Quantitative measurements of root hair growth directionality were done with ImageJ. Only root hairs with the swelling and the newly formed outgrowth in one optical plane have been taken to determine the deviation of the new outgrowth from the original growth axis. To prevent light-induced stress, low light and green filters were used during quantitative live measurements and related image recording.

\section{Whole-mount immunocytochemistry of MTs.}

For rapid freeze fixation, seedlings were taken from the Fåhraeus slides and directly plunged into liquid propane and kept there at least for $20 \mathrm{~s}$. Roots were excised and transferred into cryogenic vials, containing water-free methanol with $0.05 \%$ (vol/vol) glutaraldehyde. In this solution, roots were freeze substituted for $48 \mathrm{~h}$ at $-90^{\circ} \mathrm{C}$ and allowed to warm to room temperature over a $24-\mathrm{h}$ period. Samples were rehydrated in a graded series of methanol in phosphate-buffered saline (PBS; $137 \mathrm{mM} \mathrm{NaCl}, 2.7 \mathrm{KCl}, 1.5 \mathrm{mM} \mathrm{KH} \mathrm{PO}_{4}, 8.1 \mathrm{mM}$ $\left.\mathrm{Na}_{2} \mathrm{HPO}_{4}, \mathrm{pH} 7.4\right)$ containing fixative $(0.1 \%$ glutaraldehyde [vol/vol] and 4\% [wt/vol] paraformaldehyde). After rehydration, a partial cell wall digestion was carried out in a saturated suspension of driselase (Fluka, Buchs, Switzerland) and macerocyme R10 (Serva, Heidelberg, Germany) in 100 mM 2-morpholinoethanesulfonic acid ( $\mathrm{pH} \mathrm{6.15)}$ for $40 \mathrm{~min}$ at $35^{\circ} \mathrm{C}$. The specimens then were washed two times for $5 \mathrm{~min}$ in PBS and, to block unspecific sites, incubated for 5 min in PBS containing $0.1 \%(\mathrm{wt} / \mathrm{vol})$ acetylated bovine serum albumin $\left(\mathrm{BSA}_{\mathrm{ac}}\right.$; Aurion, Wageningen, The Netherlands) and $0.05 \%$ (vol/vol) Triton X-100 (BDH Laboratory Supplies, Poole, U.K.). The samples were incubated in monoclonal anti- $\alpha$-tubulin clone
DM $1 \alpha$ (Sigma-Aldrich, St. Louis) diluted 1:300 (vol/vol) in PBS containing $0.1 \%(\mathrm{wt} / \mathrm{vol}) \mathrm{BSA}_{\mathrm{ac}}$ and $0.05 \%$ (vol/vol) Triton $\mathrm{X}-100$ for $12 \mathrm{~h}$ at $4^{\circ} \mathrm{C}$. After washing three times for $5 \mathrm{~min}$ in PBS, the samples were incubated in anti-mouse/immunoglobulin G/Alexa 488, raised in goat (Molecular Probes, Eugene, OR. U.S.A.), and diluted 1:300 (vol/vol) in PBS containing $0.1 \%(\mathrm{wt} / \mathrm{vol}) \mathrm{BSA}_{\mathrm{ac}}$ and $0.05 \%$ (vol/vol) Triton X-100 for $12 \mathrm{~h}$ at $4^{\circ} \mathrm{C}$. Specimens were washed twice for $5 \mathrm{~min}$ with PBS and for 5 min with CITIFLUOR PBS solution (Citifluor Ltd., London), after which they were mounted in an antifading medium (PROLONG ANTIFADE, Molecular Probes).

\section{Microscopic observation \\ of MTs after immunocytochemistry.}

Antibody-labeled MTs were visualized with a BIO-RAD MCR 600 CLSM (Bio-Rad Laboratories Ltd., Hertfordshire, U.K.) with an argon-krypton ion laser attached to a NIKON DIAPHOT 300 (Nikon) inverted microscope equipped with a $\times 60$ FL 1.4 n.a. oil immersion objective (Nikon) or with a $\times 100$ FL 1.2 n.a. water immersion objective (Leitz Wetzlar, Wetzlar, Germany). Z-stacks were collected with Z-steps of 1 $\mu \mathrm{m}$. Images were acquired and projected with Confocal Assistant (version 4.02; Bio-Rad) and processed with Scion Image (beta 4.0.2; Scion Corporation, Frederick, MD, U.S.A.) and Adobe Photoshop 5.5 (Adobe Systems Incorporated, Mountain View, CA, U.S.A.).

To compare early effects of NF versus PGM on the MT cytoskeleton, for each time point per treatment the EMTs and CMTs of 40 root hairs were compared with the MT cytoskeleton of untreated young tip-growing $M$. truncatula hairs. Only root hairs with similar fluorescent signal intensity and evenly distributed fluorescent signal were imaged. The experiment was repeated twice.

\section{Microscopic observations \\ of GFP-MBD-expressing root hairs.}

For observation, the roots growing on agar were submerged in sterile water and covered with a gas-permeable plastic foil (bioFOLIE 25; Sartorius AG, Vivascience Support Center, Göttingen, Germany) to allow direct observation and to prevent them from drying. The opened dish was put on the microscope stage of a ZEISS LSM510 (Carl Zeiss SA, Le Pecq, France) and observations were carried out either with a $\times 40 / 0.8$ WPH2 Achroplan or ×63/0.9 WPH3 Achroplan objective. In general, Z-stacks were made of whole root hairs with a Z-step of $1 \mu \mathrm{m}$ between subsequent optical sections. Image projections were made with ZEISS LSM Image Examiner and images were processed with Image-Pro plus (Media Cybernetics, L.P., Silver Spring, MD, U.S.A.).

\section{ACKNOWLEDGMENTS}

B. J. Sieberer was supported by a grant from the European Community TMR Program (FMRX CT 98 0239). A. C. J. Timmers was supported by a short-term fellowship from the Advanced Light Microscopy Facility (ALMF) of the European Molecular Biology Laboratory (EMBL), Heidelberg, Germany. We thank R. Pepperkok, J. Rietdorf, T. Zimmermann, and A. Girod of the ALMF for their hospitality and help to A. C. J. Timmers during his stay at the EMBL; and T. Ketelaar for critical reading of and helpful comments on the manuscript.

\section{LITERATURE CITED}

Allen, N. S., Bennett, M. N., Cox, D. N., Shipley, A., Ehrhardt, D. W., and Long, S. R. 1994. Effects of Nod factors on alfalfa root hair $\mathrm{Ca}^{++}$and $\mathrm{H}^{+}$currents on cytoskeleton behavior. Pages 107-114 in: Advances in Molecular Genetics of Plant-Microbe Interactions, Vol. 3. M. J. Daniels, J. A. Downie, and A. E. Osbourn, eds. Kluwer Academic Publishers, Dordrecht, The Netherlands. 
Anthony, R. G., and Hussey, P. J. 1999. Dinitroaniline herbicide resistance and the microtubule cytoskeleton. Trend Plant Sci. 4:112-116.

Boisson-Dernier, A., Chabaud, M., Garcia, F., Bécard, G., Rosenberg, C., and Barker, D. G. 2001. Agrobacterium rhizogenes-transformed roots of Medicago truncatula for the study of nitrogen-fixing and endomycorrhizal symbiotic associations. Mol. Plant-Microbe Interact. 14:695700

Cárdenas, L., Vidali, L., Domínguez, J., Pérez, H, Sánchez, F., Hepler, P. K., and Quinto, C. 1998. Rearrangement of actin microfilaments in plant root hairs responding to Rhizobium etli nodulation signals. Plant Physiol. 116:871-877.

Cárdenas, L., Thomas-Oates, J. E., Nava, N., Lopez-Lara, I. M., Hepler, P. K., and Quinto, C. 2003. The role of nod factor substituents in actin cytoskeleton rearrangements in Phaseolus vulgaris. Mol. Plant-Microbe Interact. 16:326-334.

Cullimore, J., and Dénarié, J. 2003. Plant sciences: How legumes select their sweet talking symbionts. Science 302:575-578.

Cyr, R. J. 1991. Calcium calmodulin affects microtubule stability in lysed protoplasts. J. Cell Sci. 100:311-317.

Cyr, R. J. 1994. Microtubules in plant morphogenesis: role of the cortical array. Annu. Rev. Cell Biol. 10:153-180.

De Ruijter, N. C. A., Rook, M. B., Bisseling, T., and Emons, A. M. C. 1998. Lipochito-oligosaccharides re-initiate root hair tip growth in Vicia sativa with high calcium and spectrin-like antigen at the tip. Plant $\mathrm{J}$. 13:341-350.

De Ruijter, N. C. A., Bisseling, T., and Emons, A. M. C. 1999. Rhizobium Nod factors induce an increase in sub-apical fine bundles of actin filaments in Vicia sativa root hairs within minutes. Mol. Plant-Microbe Interact. 12:829-832.

Dhonukshe, P., and Gadella, T. W. J., Jr. 2003. Alteration of microtubule dynamic instability during preprophase band formation revealed by yellow fluorescent protein-CLIP170 microtubule plus-end labeling. Plant Cell 15:597-611.

Endre, G., Kereszt, A., Kevei, Z., Mihacea, S., Kalo, P., and Kiss, G. B 2002. A receptor kinase gene regulating symbiotic nodule development. Nature 417:962-966.

Esseling, J. J., De Ruijter, N. C. A., and Emons, A. M. C. 2000. The root hair cytoskeleton as backbone, highway, morphogenetic instrument and target for signaling. Pages 29-52 in: Root Hairs. Cell and Molecular Biology. R. W. Ridge and A. M. C. Emons, eds. Springer-Verlag, Tokyo.

Esseling, J. J., Lhuissier, F. G. P., and Emons, A. M. C. 2003. Nod factorinduced root hair curling: Continuous polar growth towards the point of Nod factor application. Plant Physiol. 132:1982-1988.

Esseling, J. J., Lhuissier, F. G. P., and Emons, A. M. C. 2004. A nonsymbiotic root hair tip growth phenotype in NORK-mutated legumes: Implications for nodulation factor-induced signaling and formation of a multifaceted root hair pocket for bacteria. Plant Cell 16:933-944.

Fåhraeus, G. 1957. The infection of white clover root hairs by nodule bacteria studied by a simple glass slide technique. J. Gen. Micobiol. 16:374-381

Felle, H. H., Kondorosi, E., Kondorosi, A., and Schultze, M. 1998. The role of ion fluxes in Nod factor signaling in Medicago sativa. Plant $\mathrm{J}$. 13:453-463.

Felle, H. H., Kondorosi, E., Kondorosi, A., and Schultze M. 1999a. Nod factors modulate the concentration of cytosolic free calcium differently in growing and non-growing root hairs of Medicago sativa L. Planta 209:207-212.

Felle, H. H., Kondorosi, E., Kondorosi, A., and Schultze, M. 1999b. Elevation of the cytosolic free $\left[\mathrm{Ca}^{2+}\right]$ is indispensable for the transduction of the Nod factor signal in alfalfa. Plant Physiol. 121:273-280.

Fisher, R. F., and Long, S. R. 1992. Rhizobium-plant signal exchange. Nature 357:655-660.

Geurts, R. 2003. LysM domain receptor kinases regulating rhizobial nod factor-induced infection. Science 302:630-633.

Hadri, A. E., and Bisseling, T. 1998. Responses of the plant to Nod factors. Pages 403-416 in: The Rhizobiaceae: Molecular Biology of Model Plant-Associated Bacteria. H. P. Spaink, A. Kondorosi, and P. J. J. Hooykaas, eds. Kluwer Academic Publishers, Dordrecht, The Nether-

Heidstra, R., Geurts, R., Franssen, H., Spaink, H. P., van Kammen, A., and Bisseling, T. 1994. Root hair deformation activity of nodulation factors and their fate on Vicia sativa. Plant Physiol. 105:787-797.

Ketelaar, T., and Emons, A. M. C. 2001. The cytoskeleton in plant cell growth: Lessons from root hairs. New Phytol. 152:409-418.

Ketelaar, T., De Ruijter, N. C. A., and Emons, A. M. C. 2003. Unstable factin specifies the area and microtubule direction of cell expansion in Arabidopsis root hairs. Plant Cell 15:285-292.

Kijne, J. W. 1992. The Rhizobium infection process. Pages 349-398 in: Biological Nitrogen Fixation. G. Stacey, R. Burris, and H. Evans, eds.
Chapman and Hall, New York.

Lerouge, P., Roche, P., Faucher, C., Maillet, F., Truchet, G., Promé, J. C., and Dénarié, J. 1990. Symbiotic host specificity of Rhizobium meliloti is determined by a sulphated and acetylated glucosamine oligosaccharide signal. Nature 344:781-784.

Lhuissier F. G. P., De Ruijter N. C. A., Sieberer B. J., Esseling J. J., and Emons, A. M. C. 2001. Time course of cell biological events evoked in legume root hair by Rhizobium Nod factors: State of the art. Ann. Bot. 87:289-302.

Limpens, E., Franken, C., Smit, P., Willemse, J., Bisseling, T., and Geurts, R. 2003. LysM domain receptor kinases regulating rhizobial Nod factor-induced infection. Science 302:630-633.

Lloyd, C. W., Pearce, K. J., Rawlins, D. J., Ridge, R. W., and Shaw, P. J. 1987. Endoplasmic microtubules connect the advancing nucleus to the tip of legume root hairs, but F-actin is involved in basipetal migration. Cell Motil. Cytoskelet. 8:27-36.

Lovy-Wheeler, A., Wilsen, K. L., Baskin, T. I., and Hepler, P. K. 2005. Enhanced fixation reveals the apical cortical fringe of actin filaments as a consistent feature of the pollen tube. Planta Online First, DOI: 10.1007/s00425-004-1423-2. Published online.

Madsen, E. B., Madsen, L. H., Radutoiu, S., Olbryt, M., Rakwalska, M., Szczyglowski, K., Sato, S., Kaneko, T., Tabata, S., Sandal, N., and Stougaard, J. 2003. A receptor kinase gene of the LysM type is involved in legume perception of rhizobial signals. Nature 425:637-640.

Marc, J., Granger, C. L., Brincat, J., Fisher, D. D., Kao, T., McCubbin, A G., and Cyr, R. J. 1998. A GFP-MAP4 reporter gene for visualizing cortical microtubule rearrangements in living epidermal cells. Plant Cell 10:1927-1939.

Miller, D. D., De Ruijter, N. C. A., Bisseling, T., and Emons, A. M. C. 1999. The role of actin in root hair morphogenesis: studies with lipochito-oligosaccharide as a growth stimulator and cytochalasin as an actin perturbing drug. Plant J. 17:141-154.

Parniske, M., and Downie, J. A. 2003. Plant biology: Locks, keys and symbioses. Nature 425:569-570.

Radutoiu, S., Madsen, L. H., Madsen, E. B., Felle, H. H., Umehara, Y Grønlund, M., Sato, S., Nakamura, Y., Tabata, S., Sandal, N., and Stougaard, J. 2003. Plant recognition of symbiotic bacteria requires two LysM receptor-like kinases. Nature 425:585-592.

Ridge, R. W. 1992. A model of legume root hair growth and Rhizobium infection. Symbiosis 14:359-373.

Roche, P., Debelle, F., Maillet, F., Lerouge, P., Faucher, C., Truchet, G., Dénarié, J., and Promé, J. C. 1991. Molecular basis of symbiotic host specificity in Rhizobium meliloti: nodH and nodPQ genes encode the sulfation of lipo-oligosaccharide signals. Cell 67:1131-1143.

Shaw, S. L., Kamyar, R., and Ehrhardt, D. W. 2003. Sustained microtubule treadmilling in Arabidopsis cortical arrays. Science 300:1715-1718.

Sieberer, B., and Emons, A. M. C. 2000. Cytoarchitecture and pattern of cytoplasmic streaming in root hairs of Medicago truncatula during development and deformation by nodulation factors. Protoplasma 214:118-127.

Sieberer, B. J., Timmers, A. C. J., Lhuissier, F. G. P., and Emons, A. M. C. 2002. Endoplasmic microtubules configure the subapical cytoplasm and are required for fast growth of Medicago truncatula root hairs. Plant Physiol. 130:977-988.

Spaink, H. P., Sheeley, D. M., van Brussel, A. A. N., Glushka, J., York, W. S., Tak, T., Geiger, O., Kennedy, E. P., Reinhold, V. N., and Lugtenberg, B. J. J. 1991. A novel highly unsaturated fatty acid moiety of lipo-oligosaccharide signals determines host specificity of Rhizobium. Nature 354: $125-130$

Stracke, S., Kistner, C., Yoshida, S., Mulder, L., Sato, S., Kaneko, T., Tabata, S., Sandal, N., Stougaard, J., Szczyglowski, K., and Parniske, M. 2002. A plant receptor-like kinase required for both bacterial and fungal symbiosis. Nature 417:959-962.

Thion, L., Mazars, C., Nacry, P., Bouchez, D., Moreau, M., Ranjeva, R., and Thuleau, P. 1998. Plasma membrane depolarization-activated calcium channels, stimulated by microtubule depolymerizing drugs in wild-type Arabidopsis thaliana protoplasts, display constitutively large activities and longer half life in ton 2 mutant cells affected in the organization of cortical microtubules. Plant J. 13:603-610.

Timmers, A. C. J. 2000. Infection of root hairs by Rhizobia: Infection thread development with emphasis on the microtubular cytoskeleton. Pages 223-239 in: Root Hairs. R. W. Ridge and A. M. C. Emons, eds Springer-Verlag, Tokyo.

Truchet, G., Roche, P., Lerouge, P., Vasse, J., Camut, S., de Billy, F., Promé, J. C., and Dénarié, J. 1991. Sulphated lipo-oligosaccharide signals of Rhizobium meliloti elicit root nodule organogenesis in alfalfa. Nature 351:670-673.

Van Batenburg, F. H. D., Jonker, R., and Kijne, J. W. 1986. Rhizobium induces marked root hair curling by redirection of tip growth: a computer simulation. Physiol. Plant 66:476-480. 
Van Bruaene, N., Greg, J., and van Oostveldt, P. 2004. Reorganization and in vivo dynamics of microtubules during Arabidopsis thaliana root hair development. Plant Physiol. 136:3905-3919.

Vos, J. W., Sieberer, B., Timmers, A. C. J., and Emons, A. M. C. 2003. Microtubule dynamics during preprophase band formation and the role of endoplasmic microtubules during root hair elongation. Cell Biol. Int 27:295.

Vos, J. W., Dogterom, M, and Emons, A. M. C. 2004. Microtubules become more dynamic but not shorter during preprophase band formation: A possible "search-and-capture" mechanism for microtubule trans- location. Cell Motil. Cytoskelet. 57:246-258.

Weerasinghe, R. R., Collings, D. A., Johannes, E., and Allen, N. S. 2003. The distributional changes and role of microtubules in Nod factor-challenged Medicago sativa root hairs. Planta 218:276-287.

\section{AUTHOR-RECOMMENDED INTERNET RESOURCE}

National Institutes of Health, Image $\mathrm{J}$ webpage: rsb.info.nih.gov/ij 